\title{
CONTENIDO
}

Introducción

La articulación entre lo local y lo global, riesgos

y desafíos para la relación entre arquitectura, patrimonio,

turismo y consumo de ciudad

Identidad cultural, globalización y patrimonio:

una relación a construir territorialmente.

El papel de los actores sociales en la construcción de una política orientada a integrar identidad, globalización y patrimonio en los procesos de gestión, planeación, promoción y ordenamiento del territorio

Consideraciones generales

Referencias.

Yory, C.M. (2019). Temas críticos en la relación entre identidad territorial, globalización y patrimonio. En C.M. Yory (Ed.), Identidad territorial, globalización y patrimonio (pp. 194-219). Editorial Universidad Católica de Colombia. https://doi.org/10.14718/9789585133761.2021.10

1 El presente desarrollo, que integra en un único consolidado los principales posicionamientos de los investigadores asistentes al V Coloquio Internacional organizado por la Red Internacional de Pensamiento Crítico sobre Globalización y Patrimonio Construido (RIGPAC) responde en todo a la construcción de nuevo conocimiento que de tal suerte nutre la investigación en su conjunto, toda vez que los posicionamientos de los investigadores participantes fueron levantados y posteriormente integrados a la luz de las preguntas guía formuladas a los mismos. Para este efecto se organizaron Mesas temáticas de trabajo. En tal sentido el capítulo recoge, de manera sistematizada y articulada, los principales contenidos de los debates consignados en las relatorías de las Mesas mencionadas.

2 Arquitecto, Especialista en Cooperación para el Desarrollo de Asentamientos Humanos en América Latina y África, Magister en Filosofía, Doctor Suma Cum Laude en Historia y Geografía con un posdoctorado en Antropología Social. Investigador y docente en la Universidad Nacional de Colombia y en la Universidad Católica de Colombia. Consultor y conferencista internacional en temas relacionados con el desarrollo territorial integrado y la construcción social del hábitat y el territorio. Autor de numerosas publicaciones en distintos países. Presidente de la Red Internacional de Pensamiento Crítico sobre Globalización y Patrimonio Construido, RIGPAC. Candidato por Colombia en 2015 al Premio Mundia de la UNESCO en desarrollos innovadores en ciencias sociales, artes y humanidades. https://orcid.org/0000-0002-5079-6284

cmyory@ucatólica.edu.co / alzaiir@yahoo.es 


\section{TEMAS CRÍTICOS EN LA RELACIÓN entre identidad territorial, globalización y patrimonio ${ }^{1}$}

Carlos Mario Yory²

Universidad Católica de Colombia

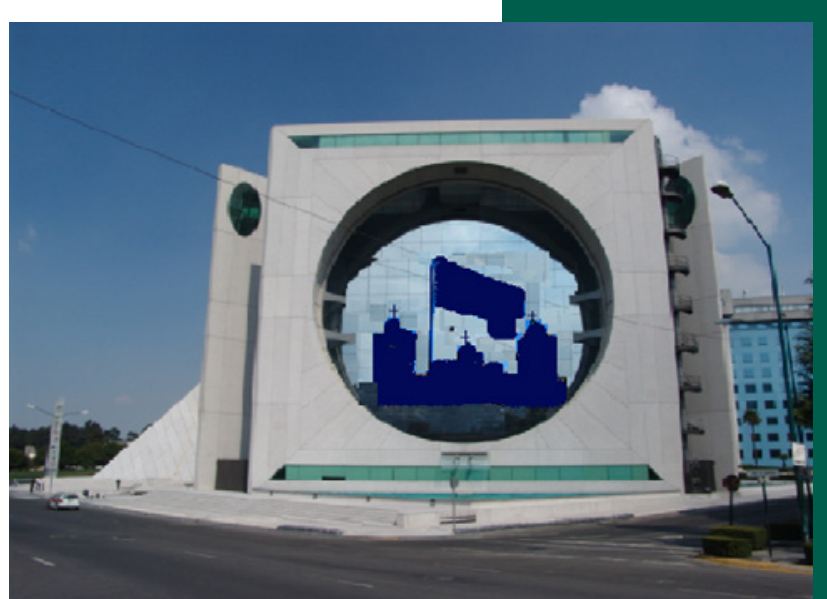

Fotomontaje Edificio del sector de Santa Fé

Carlos Mario Yory, 2009 
El presente capítulo pretende recoger las principales conclusiones del V Coloquio Internacional "Identidad territorial, globalización y patrimonio", celebrado en el marco de la presente investigación por la Red Internacional de Pensamiento Crítico sobre Globalización y Patrimonio Construido (RIGPAC), con el apoyo de la Universidad de la Salle de la ciudad de Canoas (Brasil) entre el $12 \mathrm{y}$ el 14 de septiembre de 2018.

En él se reunieron expertos, intelectuales y académicos de distintos países con el fin de debatir en torno a la relevancia o no que el concepto de identidad territorial - ligado al de patrimonio material e inmaterial- pudiera tener hoy en día en el contexto del mundo global en que vivimos, toda vez que el mismo tiende a imponer, cada vez más, códigos, hábitos, lenguajes, prácticas y valores uniformizantes; los que si por un lado amenazan con borrar los particularismos, por otro - de manera aparentemente paradójica - busca exaltarlos, en tanto "ventaja comparativa" dentro del mundo-mercado en el cual "facturan" como enluciente atractivo a la cada vez más poderosa industria cultural.

Para el efecto, el Coloquio se trazó como objetivo analizar respecto al tema de la identidad territorial:

- La situación de esta en el mundo global.

- Las formas de resistencia de la misma al proceso homogenizador que la globalización aparentemente presenta.
- Las políticas públicas que la desestimulan o alientan.

- Los impactos que la globalización trae consigo sobre ella.

- Las amenazas y oportunidades que la globalización hoy en día le presenta, y

- Los posibles caminos para empoderar el patrimonio cultural, material e inmaterial, como claro escenario para validarla, renovarla y proyectarla (Directrices planteadas para el desarrollo de las Mesas temáticas dentro del V Coloquio RIGPAC, 2018).

Desde aquí, se propusieron veintisiete (27) Mesas de trabajo que finalmente se convirtieron en 24:

- Expresiones culturales y elaboración de identidades.

- Conflictos turísticos en enclaves patrimoniales.

- Desafíos del patrimonio cultural: entre la espectacularización y las disputas territoriales.

- Conservación del paisaje como patrimonio, medio ambiente y estrategias urbanas.

- Urbanismo moderno y urbanismo contemporáneo.

- La ciudad como medio ambiente: interfaces entre la historia ambiental y la historia urbana.

- Religiones, identidad nacional y memoria cultural. 
- Tics y sentidos de lugar: dinámicas de identidad en la era digital.

- Usos del patrimonio industrial: cómo y qué preservar?

- Identidad territorial, globalización y gestión patrimonial.

- Identidad territorial (in)migrante.

- Usos y discursos del patrimonio: entre lo local y lo global.

- Tiempo-espacios educativos y construcción de identidades.

- La ciudad: espacio de expresión estético-política.

- Patrimonio industrial, identidades y conservación: desafíos globales-locales.

- Imagen, ciudad y patrimonio cultural.

- Transformación del paisaje urbano-territorial: imágenes e imaginarios.

- Apropiacion del espacio y reciclaje del patrimonio edificado.

- Accesibilidad en el patrimonio.

- Nuevos formatos en el patrimonio, gestión e inovación social.

- Construcción social del habitat en torno a la multiculturalidad y el valor del patrimonio.

- Territorios e identidades urbanas.

- El adentro y el afuera en la construcción de la ciudad popular.
En cualquier caso, reflexionando en torno a los siguientes temas consignados al interior de la convocatoria al V Coloquio Internacional RIGPAC (2018):

1. Identidad cultural: formas de expresión de la identidad; resistencias sociales y autoafirmaciones; lenguajes y discursos; inclusión/exclusión social; la participación ciudadana: retos y escenarios; vivir al límite y vivir en el límite ; gestión social y gestión de lo social; identidad y diferencia (ejemplos ilustrativos).

2. Pensamiento geográfico y memoria cultural: Teorías pertinentes; líneas de investigación en ciencias sociales, ambientales y del hábitat; resiliencia urbana y territorial, líneas y fronteras (ejemplos ilustrativos).

3. Neoliberalismo, globalización y sentido de lugar: flujos de sentido y flujos de capital; identidad y nuevos paradigmas civilizatorios; globalización económica y cultural; legitimidad y hegemonía; ¿De qué tiempo es este lugar?; la ciudad como escenario y como bien de consumo (ejemplos ilustrativos).

4. Periferialización y neocolonialismo: formas de expresión neocolonial; nuevos ejercicios del poder y nuevos formatos para la relación centro-periferia; el poder de las minorías; los neorelatos en el gobierno de la ciudad; la emergencia de la ciudadanía y la resemantización de lo público; espacios sociales, umbrales territoriales y nuevas fronteras (ejemplos ilustrativos). 
5. Consumo, globalización y patrimonio: ¿Vencer o convencer?; la realidad de "la copia"; la identidad territorial en el mundo mercado; centros comerciales y mercados populares; la ciudad como bien de consumo; centros históricos y "centros histriónicos" (ejemplos ilustrativos).

6. City marketing, patrimonio y marca de lugar: Impactos territoriales de las políticas públicas en los entornos urbanos patrimoniales; la "edición del lugar" destinada a su promoción internacional; Impactos locales de los imaginarios globales; la privatización de lo público en el aprovechamiento particular de los bienes colectivos; la marca de lugar: ¿una ventaja o una condena? (ejemplos ilustrativos).

7. TICs y sentido de lugar: Redes sociales y nuevos espacios públicos; el control y manejo de la opinión; información y conocimiento; ¿quien manda a quién?; vivir en la red y vivir "enredado"; poderes, contrapoderes y neopoderes (ejemplos ilustrativos).

8. Paisaje cultural, imagen de ciudad y conservación patrimonial: Impactos territoriales de la renovación urbana; formas de vida y transformaciones culturales; costos sociales e impactos ambientales; amenazas y oportunidades desde la globalización; construcción o destrucción local de sentido (ejemplos ilustrativos).

9. Territorializaciones, desterritorializaciones y reterritorializaciones: Intervenciones sobre los entornos patrimoniales; equilibrios y desequilibrios territoriales; ¿Depredación o aprovechamiento?; texto, contexto y pretexto en el tratamiento de los patrimonial (ejemplos ilustrativos).

10. Arquitectura de lugar: ciudad formal e informal; nuevas formas de apropiación socio-espacial; la construcción territorial de paisaje; tras la huella en la piedra; usos nuevos para edificios antiguos, la materialidad arqui-tectónica; lenguajes y gestos; conservación y restauración; mímesis y contrastes; los múltiples sentidos de la apropiación socio-espacial; la (re) construcción de sentido (ejemplos ilustrativos).

11. Operaciones urbanas y neo-realismo financiero: ¿De quién es la ciudad? ¿Qué tan públicas son las políticas públicas de renovación urbana? Resistencias, insistencias y persistencias sobre el espacio común de la ciudad; Gentrificación; ¿Es posible renovar sin desplazar?: esquemas alternativos; Política pública y beneficio privado; la participación ciudadana en la construcción de ciudad; planeación participativa y coadministración territorial; Alianzas público-privadas (ejemplos ilustrativos).

12. Urbanismo moderno y urbanismo contemporáneo: Nuevas formas de pensar la ciudad desde lo patrimonial; ¿cambiando "lámparas viejas" por "lámparas nuevas"? la construcción social del hábitat; nuevos desafíos para la vivienda; ciudad compacta, ciudad dispersa y ciudad difusa; el reto de la multiculturalidad; conflictividad y convivencia (ejemplos ilustrativos). 
Temas generales que en última instancia pretendían responder a las siguientes preguntas orientadoras consignadas al interior del consecuente Protocolo de Investigación inscrito en la Universidad Católica de Colombia (2018):

1. ¿Cómo articular, desde una política concebida a partir de la relación entre identidad, globalización y patrimonio, demandas globales con desafíos locales y, a la vez, demandas locales con desafíos globales?

2. ¿Cómo puede construirse una relación armónica y responsable entre identidad cultural, globalización y patrimonio?

3. ¿Cuál debe ser el papel de los diferentes actores sociales en la construcción de una política orientada a integrar armónica y responsablemente, identidad territorial, globalización y patrimonio en los procesos de gestión, planeación, promoción y ordenamiento del territorio?

Para el efecto, la metodología que se siguió supuso la realización, en las mañanas, de una serie de conferencias magistrales transversales a los intereses de los ejes temáticos planteados como provocación para que, en las tardes, se efectuara un debate inter y trans disciplinar con los asistentes, derivado de su posicionamiento personal frente a los temas a través de las ponencias que para el efecto oportunamente inscribieron en una $u$ otra Mesa de trabajo.

Valga señalar que, si bien el contenido siguiente se debe en gran medida a una transversalización de los aportes de los asistentes, recogidos por los relatores del Coloquio en respectivos resúmenes, la responsabilidad de su integración como reflexión consolidada recae exclusivamente en su autor, quien, de paso, agradece especialmente la colaboración en la elaboración de dichas relatorías de las personas relacionadas en la nota al pie de página ${ }^{3}$, excusándose de posibles omisiones involuntarias.

En el mismo sentido, el autor no solo extiende su agradecimiento a todas y a cada una de las personas que a través de sus valiosos aportes hicieron posible tanto la realización del Coloquio mencionado como el modesto y siempre insuficiente ejercicio de consolidación que se recoge ahora en las siguientes páginas, sino que se ve en la necesidad de pedir disculpas a los numerosos participantes en las Mesas de trabajo (más de 300) por omitir al interior del presente ejercicio sus nombres por cuestiones de espacio.

Del mismo modo señala que para efectos de fluidez del discurso, este se estructura de manera autónoma - desenmarcándose de los desarrollos de las Mesas- con el fin de desplegar unos contenidos transversales que de una $\mathrm{u}$ otra forma respondan a los tres interrogantes trazados a la luz del objetivo general mencionado.

\footnotetext{
Renato Machado, Julio Cezar, Roberto Goycoolea, Laura Zamudio, Darlan de Mamman, Juliana Poloni, Fabiola Colmenero, Alfredo Perez, Judite de Bem, Heleniza Campos, Danielle Heberle, Eduardo Relly, Artur Cesar Isaia, Renata Ambroziak, Patricia Kayser Vargas Mangan, Tatiana Vargas Maia, Ana Paula Vargas Maia, Catherine Rosas, Susana Domingues, Renato Machado, Jorge Kulemeyer, Michel Kobelinski, Carlos Antaramián, Heitor Loureiro, Eduardo Roberto Knack, Maíne Barbosa, Marlise Buchweitz, Dirlei de Azambuja, Daniela Tomeo, lliana Mignaqui, Carolina Quirtoga, Carolina Etcheverry, Cesar Vieira, Jaime Silva, Vanessa da Silva, Sergio Rodrigues, Eugenia Salomao, Laura Ibarlucea, Ana Clarissa, Rita de Cássia e Daiana Guadalupe Gama, Edgar Roa Castilho, Ricardo Contreras, Robinson Silva, Boris Cofrés, Romelia Gama y Pedro Couto Moreiro.
} 


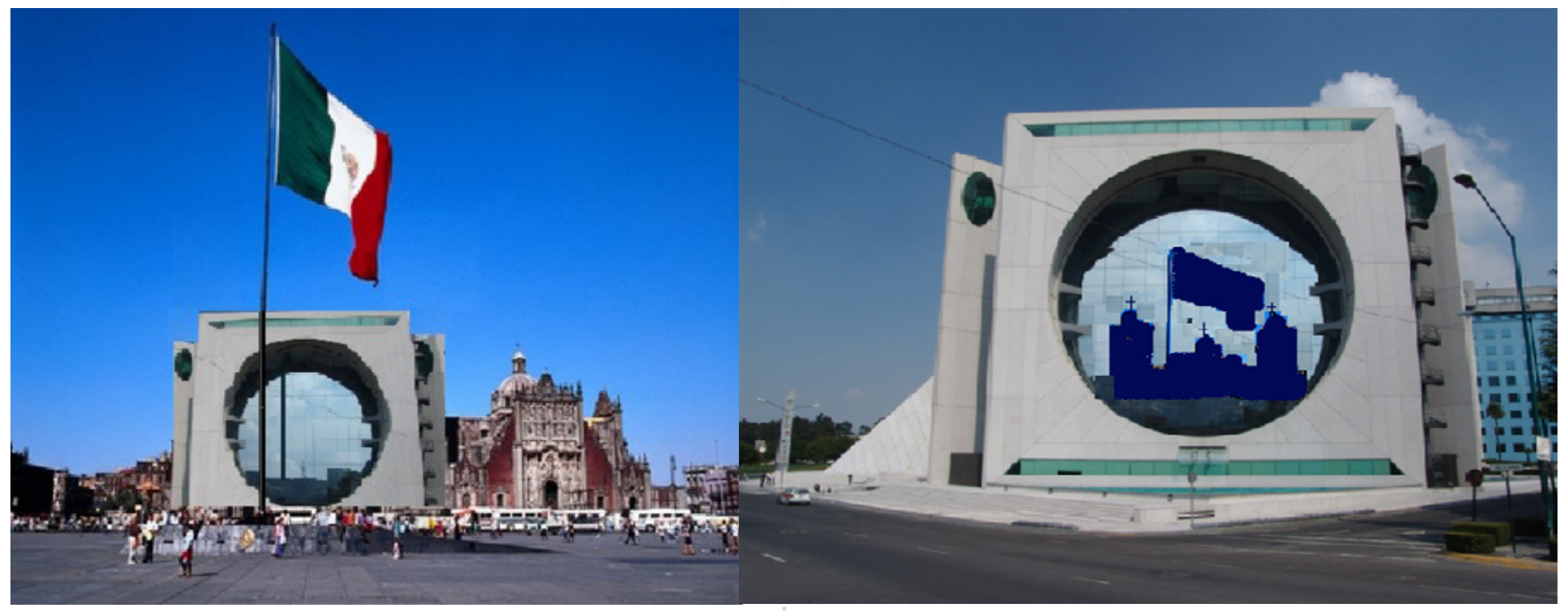

Figura 1 y 2. Fotomontaje Edificio del sector de Santa Fé

Nota. Fotomontaje edificio del sector de Santa Fé inserto en el Zócalo de la Ciudad de México y Zócalo de la Ciudad de México alegóricamente reflejado sobre el mismo edificio ubicado en el sector de Santa Fé. Fuente: Carlos Mario Yory (2009).

Por tal motivo, el criterio de consolidación de la reflexión no responde a una recopilación aditiva de ideas enmarcadas en los desarrollos particulares de cada Mesa, o de cada participante, sino a uno de articulación que, en tanto recurso intelectual, si bien pretende recoger el espíritu y los resultados de cada una, de suyo compromete la visión del autor que en consecuencia asume la tarea y los riesgos de presentar un producto que de tal suerte pretende ser integrado.

\section{La articulación entre lo local y lo global, riesgos y desafíos para la relación entre arquitectura, patrimonio, turismo y consumo de ciudad}

Parece ser que uno de los signos de la globalización es la adopción, acaso imposición, de un tipo de ciudad, de un tipo de consumo y hasta de un tipo de patrimonio; en este último caso cada vez más alejado de las características históricas, sociales y culturales que lo generaron (Figuras 1 y 2).

En tal sentido, los procesos de intervención del territorio, con fines frecuentemente especulativos, ya sea en el orden habitacional, empresarial, institucional, comercial o turístico han generado una serie de conflictos en las áreas habilitadas para estos, tanto en centros urbanos como en entornos rurales y periféricos afectando especialmente el desarrollo local de las comunidades y lo que estas, desde su experiencia vivida y sus formas de apropiación y significación del espacio, asumen y adoptan como su patrimonio.

De esta suerte, se presenta un cierto tipo de enfrentamiento entre lo que los expertos denominan patrimonio, a la luz de unos estándares internacionales (globales) establecidos por las agencias 
pertinentes y lo que las propias comunidades localmente denominan de tal forma. El punto delicado estriba en la manera como la política pública, en cada caso, se pronuncia y posiciona en la materia al privilegiar, o no, uno u otro discurso. Pero ¿estamos en realidad hablando de dos tipos de patrimonio? ¿Es tan distinto el que proporcionan las piedras al que ofrece la experiencia vivida de lo que ocurre en medio de ellas?

Si bien el denominado patrimonio urbano-arquitectónico, que a capa y espada defienden los especialistas, responde a lógicas, intereses y estéticas enclavadas en otro tiempo, el devenir de la ciudad en el que el mismo se inscribe lo reclama en el presente de una u otra manera: por un lado están los especuladores, que de manera parasitaria quieren servirse del mismo poniéndolo a facturar al servicio del turismo y, por otro, están los habitantes que crecieron en medio de este y de una manera u otra los sienten y experimentan como propio.

Resultado de lo primero, el enlucimiento del bien patrimonial poniéndolo al servicio de la industria turística, o bien de manera museográfica y monumentalista congelándolo de tal suerte que la forma de tratarlo imponga sobre el mismo una relación objetual-reverencial, y por tanto alejada y lejana del espectador. Lejana físicamente y alejada simbólicamente en tanto a este "no le dice nada" en razón de que el contacto con el mismo no trasciende el plano de una simple anécdota apenas registrada en una fotografía; o bien de manera viva reciclándolo y poniéndolo a interactuar con la ciudad actual a través de un nuevo uso, en cualquier caso compatible con el orden turistificante que de tal suerte impone la aldea global (Yory, 2002).

En este último caso - de espaldas a todo criterio de los expertos y patrimonialistas — valga señalar el papel que, desde el criterio del consumo, entendido como número de visitas, entra a calificar el valor de uno u otro bien a través de plataformas virtuales o páginas web como Trip Advisor cuyo sticker le otorga "dignidad y estatus" al bien patrimonial visitado. Hablamos aquí, entre otras cosas, de hoteles boutique, restaurantes de alto nivel, anticuarios o tiendas especializadas ubicadas al interior de bienes patrimoniales para tal efecto reconvertidos y reutilizados.

Resultado de lo segundo, tenemos experiencias que van desde la cada vez más rara conservación de lo que para cada comunidad es su patrimonio natural o cultural hasta la reutilización de los bienes convencionalmente denominados patrimoniales, en función del servicio que presten, a través de nuevos usos, a la propia comunidad: bibliotecas, centros culturales, recreativos o artísticos, aulas múltiples, etcétera.

Tenemos pues dos tendencias entre las cuales vibra la valoración del patrimonio cultural urbano-arquitectónica, oscilante siempre en medio de los flujos e intereses que impone la globalización - valga decir las dinámicas de oferta y demanda del mercado- en cualquier caso al servicio del turismo o del consumo de ciudad: una que apunta a la museografización idealizante y otra que responde a una 


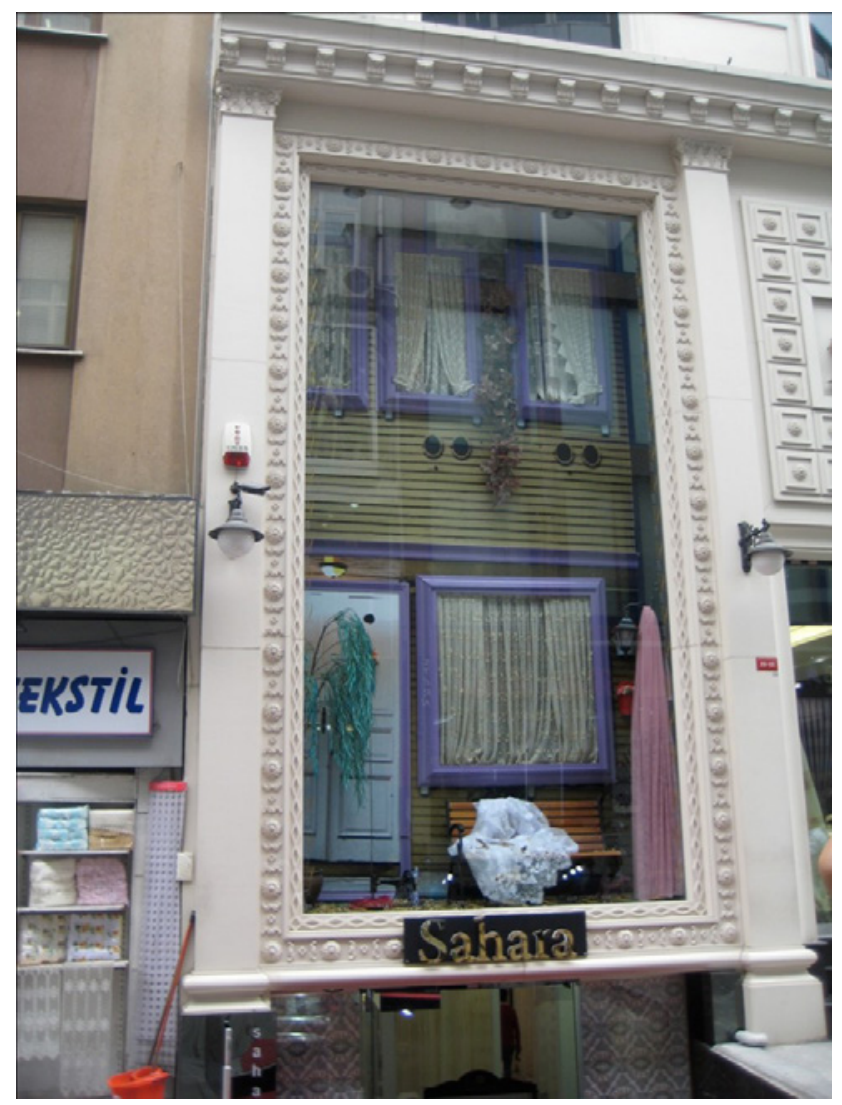

Figura 3. Museografización de fachada

Nota. Museografización de fachada de una vivienda ubicada en un barrio tradicional de Estambul bajo forma de vitrina publicitaria. Fuente: Carlos Mario Yory (2012).

pragmática reutilización. En este último caso, el peligro viene de parte de una posible desnaturalización y/o descontextualización del bien patrimonial (pérdida de significación del bien) y de su entorno histórico (desaparición de la memoria del lugar) como consecuencia de la asignación de nuevos usos o de su turistificante exotización (Figura 3).

Lo que aquí ocurre es que a través de la arquitectura se intenta ligar un contexto patrimonial con el aspecto principal que, a la luz de una idea particular de city marketing, se le quiere otorgar a la ciudad en la perspectiva de acuñar una diferenciadora "marca de lugar".
La transposición de elementos arquitectónicos, el trasplante de los mismos a lugares que no son los originales, la creación de espacios ficticios sirviéndose de estos, la caricaturización y espectacularización de los mismos por medio del pintoresquismo creando convenientes escenografías que estereotipan los discursos urbanos son prueba fehaciente de ello.

Así, tienen lugar innumerables transformaciones que, como si se tratara de una cuidadosa paleta de colores, estandariza no solo los lenguajes sino los usos urbanos frecuentemente al servicio del comercio, el consumo y/o el gran capital. En este contexto, el tipo de arquitectura que se rehabilita, recicla, reutiliza y re-inventa poco o nada tiene en cuenta a la población local, produciéndose frecuentemente el reemplazo de la misma en la medida que esta queda cada vez más fuera de la posibilidad de su usufructo cultural.

En cualquier caso, la víctima aparente de esta manera teatral y espectacularizante de entender el patrimonio tiende a dejar de lado la gente y lo que a ella de manera material o inmaterial este le significa en sus escalas micro, vecinal o barrial.

No es de sorprender que numerosos proyectos fracasen porque sus arquitectos desconocen las características y realidades de los lugares donde se llevan a cabo, toda vez que si, por un lado, la arquitectura cobra cada vez mayor preponderancia en el alistamiento formal de la ciudad de tal forma que incremente su atractivo, por otro, el correlato turístico que suele acompañar tal decisión, muchas 
veces tiene como lógica de partida los itinerarios vinculados con el consumo de productos elaborados en esos mismos lugares y no la cotidianidad, el uso habitual o la memoria de los mismos, impidiendo de tal suerte, no solo su justa valoración sino, lo que es más grave aún, su verdadera comprensión y apropiación.

En tal sentido, se puede afirmar que existe una arquitectura creada, transformada o readaptada para dar fuerza a una idea o discurso homogéneo o especializado de ciudad, que no corresponde con la función original de los lugares en los cuales se asienta.

Innumerables ejemplos dan cuenta de la importancia de la formulación de programas de usos mixtos que no "museifiquen" el bien patrimonial sino que lo reinserten en los procesos y dinámicas urbanas actuales, de ahí la importancia de expandir conceptos especializados como el de "patrimonio industrial" al ámbito del "itinerario cultural", donde el mismo pueda ser absorbido dentro de la lógica del paisaje cultural que introduce la dimensión territorial en la lectura de lo patrimonial, eso en el entendido de que tal operación no se debe sustraer de la comprensión de los procesos históricos que dieron lugar a tales o cuales formas de patrimonio, pues dichos procesos son ya un patrimonio en sí mismos.

He ahí la relevancia que cobra una investigación en la materia que se ocupe de identificar las fases o etapas clave de tales procesos y los signos socio-espaciales de cada uno de ellos: cambios en las tecnologías productivas, irrupción de la cadena de frío, inclusión de nuevas fuentes energéticas, nuevas maquinarias y procesos productivos, etcétera; los cuales, de suyo dejan su huella en el espacio-tiempo afectando formas de vida, prácticas culturales, relaciones interpersonales (no solo entre el patrono y el obrero) y, por supuesto, actitudes, posiciones y actuaciones frente al Estado, frente al mercado, frente a la sociedad, frente a la historia y frente a la naturaleza, siendo todo esto, independiente de sus resultados, positivos o negativos, según como los juzgue la historia, un patrimonio que nutre $\mathrm{y} d a$ cuerpo a un consecuente relato territorial.

Un aspecto puntual que en el caso del patrimonio industrial merece destacarse como clara muestra de identidad territorial es el que tiene que ver con la relación entre paisaje cultural, identidad territorial y reciclaje, pues la recuperación y rehabilitación de las industrias es una problemática que no solo debe contemplar la necesidad de otorgarle un nuevo uso a sus edificaciones, sino considerar como patrimonio, también, el conocimiento tradicional y tecnológico que se puso en obra, tanto para levantar tales edificaciones, como para darles uso y sentido.

En el mismo sentido, no se puede negar el carácter patrimonial del modelo organizacional que posibilitaba la producción, el cual creó unas determinadas formas de vida, un sistema de relaciones conflictivo o no- y un sentido de comunidad. A fin de cuentas, este conocimiento en muchos casos ordenó el territorio y ayudó a conformar el paisaje cultural de muchas ciudades influenciadas por estas industrias. No solo eso, aún existen personas $\mathrm{y}$ familias que son parte de ese patrimonio vivo $\mathrm{y}$ 
que, por lo mismo, probablemente aún llevan mucho de esa forma de vida en su existencia actual.

El punto es que resulta de muy difícil articulación, acaso innecesaria, tales formas de patrimonio intangible con la puesta en valor de los inmuebles que, en su momento, y gracias a sus particulares dinámicas, les dieron origen. ¿Qué hoy en día sea anacrónico el objeto patrimonial hace que lo sea también el sistema de valores y relaciones que el mismo impuso? Probablemente, pero eso no quita que el mismo actúe hoy en día y por tanto, aunque anacrónico, resulte vigente, incluso, peligrosamente vigente dadas las dinámicas autoritarias, excluyentes, segregacionistas, clasistas, sexistas y racistas que en su momento impuso la relación patrón-obrero en respuesta al "espíritu de los tiempos"... Forma de patrimonio que, hay que decirlo, de otra parte fortaleció lo sindicatos, las asociaciones temáticas y la contemporánea reivindicación de los derechos y de la equidad humana.

Pero, más allá de las variables del legado que hoy en día nos arroja el patrimonio industrial, o de las secuelas del mismo para el debate patrimonial -a fin de cuentas, la noción de patrimonio comporta todo un paquete de valores heredados que, gústenos o no, nos marcan sin que esto suponga que nos condicionen - lo que ahora interesa a la reflexión es el nuevo uso que se le otorga a tales edificaciones, o bien museificando el relato a través de posters o de fotografías de la época dispuestas para el turista explorador, o bien suprimiendo el mismo por la vía de otorgar al edifico un nuevo uso sin ninguna relación o conexión con su origen.

Sobre el particular es de lamentar, no solo el vacío normativo presente en muchos países para abordar el tema, sino la falta de un enfoque historicista que no responda, simplemente, al atractivo rentabilista de la explotación de una imagen desprovista hoy de contenido que de tal suerte reemplaza, sin más, valor de uso por valor de cambio. Debilidades a las cuales se suman los obstáculos que se presentan a escala local, provincial o regional para asumir la gestión de tal tipo de patrimonio, esto para no hablar de las dificultades de adaptación de los edificios industriales como usinas eléctricas, frigoríficos y fábricas, cuyas cadenas de montaje presentan, no solo desafíos técnicos y tecnológicos para su refuncionalización, sino para la reasignación de nuevos usos.

No obstante, no se debe olvidar que el territorio, que por definición comporta un valor patrimonial, es una construcción social que implica la transformación y el uso efectivo de un espacio físico o virtual determinado en medio de un proceso durante el cual emerge simultáneamente la identidad tanto individual como colectiva en el marco de dinámicas que comportan situaciones de desterritorialización y reterritorialización (Haesbaert, 2011) donde si bien la adopción de códigos globales tiende a desterritorializar el espacio homogeneizando el paisaje, la pervivencia, por insistencia o por resistencia, de los códigos locales tiende a reterritorializar el 
mismo fragmentando dicho paisaje así rayado por diversidad de símbolos y lenguajes.

En esta última tónica se presentan buena parte de las ponencias que, al ilustrar la situación con casos concretos, trascienden en todo el simple tono de reclamo o de denuncia; de esta forma se promueve al interior de las Mesas de trabajo un espíritu proactivo que invita al reconocimiento y valoración de la historia de los lugares que habitamos, con el fin de establecer aquellas especificidades y conocimientos particulares que, por resultar únicos, los convierten en patrimoniales. Al fin y al cabo, en cualquier caso, anuncian las formas de vínculo de cada comunidad con los lugares por ellas habitados.

Si bien esta es una aspiración loable, el hecho es que nos encontramos ante un fenómeno sin precedentes de banalización y espectacularización del espacio habitado, cuya imagen se pone en circulación a través de diferentes propuestas publicitarias que de tal forma los ofrecen en el mercado indicando dónde se debe transitar, hacia donde hacerlo e, incluso, cómo llevar a cabo ese tránsito desde la óptica del consumo (Yory, 2006). Situación en la cual resalta el rol de la publicidad en la promoción de imágenes de ciudad en las que se enfatizan estereotipos, lenguajes, estilos y gustos, de suerte tal que unos y otros establecen o encarnan cierto tipo de valores e imaginarios.

En este contexto, el discurso que los medios de comunicación oficializan suele dejar fuera la compleja e imbricada realidad de las ciudades, congelando la historia y, con ella, el patrimonio, de forma tal que memoria y vida cotidiana resultan afectadas al ser editadas bajo la forma de un discurso oficialista que tiene respuestas, explicaciones y, en muchos casos, culpables para todo.

Resultado de este proceso de simplificación de la historia, y con ello, de lo real, una higienización de la misma por la vía de la supresión, invisibilización u omisión de las diferencias, de los particularismos $\mathrm{y}$ de los discursos alternativos que, a su manera, también tienen su lectura respecto de lo que cabe denominar patrimonio o, incluso, bien patrimonial.

Cabe recordar en este sentido una frase del geógrafo brasilero Milton Santos quien a propósito de la relación entre los individuos y el entorno que habitan, visitan o frecuentan, anota: "Quando o bomem se defronta com um espaço que não ajudou a criar, cuja história desconhece, cuja memória lhe é estranha, esse lugar é a sede de uma vigorosa alienação" (Santos, 2008, p.328). El mensaje de tal afirmación va en la tónica de resaltar la importancia de cultivar sobre el espacio geográfico la relación entre conocimiento, vivencia, co-creación y, sobre todo, apropiación. Aspectos fundamentales, no solo en la construcción y valoración de la memoria individual y colectiva, sino en los procesos de formación ciudadana que puedan llevarse a cabo desde la óptica de una auténtica educación patrimonial.

En lo que respecta al papel del turismo en los procesos de des-adscripcionalidad territorial contra los cuales resulta pertinente la reflexión de Santos (2008) antes señalada, cabe mencionar el hecho de 
que su mirada particular(izada) frecuentemente omite una lectura relacional del contexto en el que, a ojos del turista, fulgen sus respectivos atractivos; esto en gran medida debido a la "edición" del contexto que para el efecto realizan los operadores turísticos bajo la forma de las vistas guiadas, mismas que de suyo orientan la mirada, resaltan o descartan unos $\mathrm{u}$ otros valores $\mathrm{y}$, de tal suerte, entran a presentar una imagen de los lugares visitados muchas ajena a la realidad, esto sin contar con el hecho de que tales recorridos no dejan en la libertad de transitar a los visitantes y, por lo mismo, de sacar sus propias conclusiones.

Desde aquí es claro que el turismo, la uniformización o edición del paisaje, la industria hotelera y el comercio han transformado los centros históricos y las narrativas e imaginarios que, a partir de ellos, locales y visitantes de diversa manera realizan o formulan.

No es de extrañar, entonces, que las estrategias de desarrollo turístico no consideren el capital cultural y social de la comunidad — salvo que el mismo "facture" de alguna manera al interior de la ciudad-mercancía- lo cual suele venir acompañado de la importación o adecuación de sistemas exógenos que de tal suerte vienen a (re)ordenar el paisaje de la ciudad sin tener en cuenta, para nada, el desarrollo de un diálogo entre la realidad existente y la que impone la plataforma turística habilitada.

Resultado de esto, en muchos casos, un esquizofrénico montaje en el que, por un lado, se tienen actividades y muestras culturales tradicionales sobre una ciudad "lisa" y descontextualizada y, por otro, se tiene una ciudad conservada como escenografía para un universo de actividades turistificantes o turistificadas contemporáneas.

La pregunta en este punto tendría que ser por el impacto de una u otra situación, no solo sobre el espacio habitado, sino sobre las formas específicas de habitación, es decir, sobre la comunidad y sus prácticas culturales y cotidianas. Esto en la perspectiva tanto de prever dichos impactos, evitándolos o amortiguándolos, como de generar estrategias responsables y sostenibles de intervención y habilitación de sectores de valor patrimonial para fines turísticos.

En cualquier caso, en el Coloquio se puso de manifiesto la preocupación frente a los conflictos que el turismo en sus diferentes vertientes está provocando en los territorios, en el patrimonio y en las formas de percibir y de vivir el espacio, tanto para los residentes, como para los propios turistas.

Sirva de referencia, en el caso de Europa, el ejemplo de Vitoria-Gasteiz (España) donde, como en tantos otros casos, se pone de manifiesto el interés de la política pública en revitalizar su centro histórico, aparentemente con éxito para el turismo, pero a costa de un sentido fracaso en lo que respecta a las expectativas de los residentes, quienes, a pesar de que se manifiestan en favor de las intervenciones urbanas y arquitectónicas de la zona que se pretende turistificar, no se identifican emocionalmente con ellas. 
Por su parte, en el caso de América Latina, los ejemplos del estudio del Barrio Histórico de la ciudad de Colonia del Sacramento, en Uruguay y, entre otros, de Cartagena de Indias, en Colombia, ponen de manifiesto los riesgos que los procesos de patrimonialización mercantilista y turistificante acarrean para la percepción y la vivencia de la ciudad histórica - tanto para locales como para visitantes - toda vez que la misma tiende a despoblarse de sus pobladores originales, ya sea porque, a la luz de un inducido proceso de especulación inmobiliario se ven forzados a vender sus propiedades - frecuentemente a extranjeros o a grupos hoteleros o inmobiliarios - ya sea porque se ven expropiados en beneficio de un consecuente proyecto que beneficie al modelo de ciudad impuesto o adoptado o, sencillamente, porque el proceso de encantamiento urbano que acompaña la escenografización teatralizante de su territorio, así banalizado y puesto en valor al servicio del consumo y la renta especializada, efectivamente los deja del todo desencantados...

Es en este sentido que la globalización se manifiesta, cuando no en el efectismo particularista y sensacionalista de la realización emblemática del tipo Museo Guggenheim de Bilbao que de tal suerte pretende "marcar" un lugar —en este caso una ciudad de tal forma "puesta en venta"-, en la homogenización arquitectural que de tal suerte opera de forma perversa en razón de que destruye, inmediata o paulatinamente, la historicidad y la pluralidad individual y socio-histórica al alterar, cuando no transformar, una identidad local y, por lo mismo, un patrimonio.

Un caso particularmente aberrante de destrucción del patrimonio cultural, específicamente arquitectónico, es el que se deriva del argumento de no repatriación de tales bienes a sus lugares de origen, con el pretexto de que los mismos están "mejor" en los museos de las metrópolis que en su momento los saquearon y robaron piedra por piedra pues, a fin de cuentas, sostiene dicho argumento, en los museos puede verlos mucha más gente que la que podría vistarlos en sus auténticos y originales contextos.

De esta forma, estos "detentores" y autodenominados "guardianes del patrimonio de la humanidad", paradojicamente lo hacen suyo, no solo negando el derecho de los pueblos donde el mismo vio la luz, en razón de determinadas situaciones de tiempo y contexto, sino explotándolo y rentabilizándolo a su mejor conveniencia.

Desde esta fundamentación -claramente imperialista - y del ingenuo y cómodo carácter consumista de nuestros tiempos, habrá quien crea que lo que ve en el Museo de Berlín es el auténtio altar de Zeus de Pérgamo que, gracias a los méritos de la civilización, tiene a su alcance a la salida de un Metro que de tal suerte le evita el desgaste, el costo y la molestia de adentrarse en una aventura incierta al centro de Turquía. ¿No hace acaso parte del templo el olor de las flores que lo vieron nacer, la sombra del arbol que lo protegió de los implacables 
veranos, el perfil de las montañas que le dieron marco y los caminos que a través del mundo antiguo le dieron razón y sentido? ¿En verdad se puede afirmar que dicho templo, sacado de su entorno, es en verdad el templo de Zeus?

¿Qué decir de la relación dominación-autonomía en el discurso patrimonial que de tal forma enfrenta los museos a las razones y los sentidos de los pueblos? Más aún, ¿Qué decir de la relación entre contemplación burguesa y valoración cultural in situ? Si bien los caminos que hoy llegan al altar de Zeus no son los recorridos por Alejandro y sus huestes "culturizantes", y hace ya rato los ciclos de la naturaleza cambiaron el árbol que lo vió nacer en medio del jardín florido de la pradera turca, no podemos desconocer el hecho de que haber privado a dicho altar del devenir histórico y natural de 2.300 años de civilización y de barbarie lo han, no solo sacado de su contexto, sino de su historia, de la cual, quien sabe, unas cabras pastando sobre él serían un mejor destino que el bombardeo de flashes de las cámaras fotográficas en la sala de un museo.

De esta suerte, la relación entre turismo y patrimonio resulta claramente conflictiva, particularmente cuando este último se declara de interés con el fin principal de comercializarlo para el consumo turístico y de masas, lo cual pone de manifiesto, entre otras cosas, el preocupante efecto sobre la capacidad de carga de los territorios así "bendecidos" o "maldecidos", según como se vea, por el paradójico peso que les otorga una Declaratoria patrimonial.
En tal situación, la falta de una adecuada política bien puede hacer que la virtud patrimonial de un territorio se convierta en su principal defecto, en razón de que aquello que alienta su atractivo derive en una lenta pero segura condena que a la postre termine agotando el mismo. Desde esta perspectiva, las consecuencias de no tener en cuenta de manera responsable los límites de la capacidad de carga de los entornos patrimoniales acarrea un peso, no solo físico, infraestructural y ambiental, sino simbólico y, en cualquier caso, político.

La pregunta no puede ser otra: ¿Cuáles son las soluciones posibles para disminuir los efectos negativos del turismo sobre los bienes y los entornos patrimoniales? Al fin y al cabo, se trata de una industria cada vez más importante cuyo peso en la economía no se puede desconocer, pero tampoco dejar libre a la inercia de las leyes del mercado. En este punto el Coloquio, en términos generales propuso:

- Incluir, equilibrar y armonizar los usos turísticos con los residenciales a través de una mixtura responsable entre unos y otros que no termine expulsando a los residentes.

- Evitar la mirada a corto plazo que frecuentemente acompaña las iniciativas rentabilistas, por una responsable y sensata que prevea impactos y sea capaz de enfrentarlos de manera oportuna y asertiva.

- Alentar las prácticas culturales tradicionales que en cualquier caso refuercen el capital simbólico 
y, por lo mismo, la dimensión inmaterial de lo patrimonial.

- Incluir en las decisiones y acciones de la política, la planeación y la gestión turística a los habitantes locales y a los académicos, de manera tal que se formulen proyectos de intervención que conciban sistemas de ordenamiento y gestión que permitan la coexistencia de sistemas exógenos y locales capaces de generar un mutuo beneficio.

- Concebir y llevar a cabo, de manera multiactoral y, por lo mismo, participativa, planes integrales de manejo capaces de armonizar los intereses de los diferentes actores sociales.

\section{Identidad cultural, globalización y patrimonio: una relación a construir territorialmente}

En lo que concierne a la relación entre los tres conceptos centrales del Coloquio, numerosos posicionamientos enriquecieron el mismo a través de ejemplos concretos que dan cuenta de la importancia de construir local y territorialmente dicha relación, toda vez que, de no ser así, bien pueden escaparse toda una serie de aspectos intangibles que, como clara muestra de identidad cultural, solo los actores locales conocen, en tanto hacen parte de las narrativas y de los discursos propios de cada lugar.

Por ejemplo, en el caso de la ciudad de Medellín, a lo largo de la calle Ayacucho se evidencian formas de apropiación socio-espacial por parte del comercio informal, que dan cuenta de dinámicas de legitimización y resistencia desde las cuales ponen en obra sus respectivas identidades locales, las cuales contrastan con la proyección de la imagen modernizante, ordenada y "enluciente" que, entre otras operaciones urbanas, impone la presencia del metro aéreo, obra que realizada en convenio entre el municipio y la Agencia Francesa para el Desarrollo (AFD), generó innumerables conflictos económicos, inmobiliarios, políticos, sociales, ambientales y patrimoniales.

De otra parte, en la ciudad de Chuquis ubicada en la provincia de la Rioja, Argentina,se pone de manifiesto la importancia patrimonial del paisaje sonoro en tanto clara muestra de identidad territorial, como lo evidencia el hecho de las numerosas calles y lugares que, por ejemplo, con ocasión de la celebración de los 80 años de su "hijo pródigo", Ramón Navarro, aluden a la zamba y, desde aquí, exaltan con orgullo el folclor argentino. Muestra clara de un proceso de activación patrimonial que involucra la entrada en valor de memorias individuales y colectivas que actúan, de esta suerte, como matriz de una sensibilidad específica que no se deja reducir a imposiciones vanas o generalizantes.

Sobre esta particular llama la atención el proceso de edición patrimonial que alrededor de la década de los años 40 del siglo pasado visibilizó o invisibilizó en muchos países de América Latina, no solo bienes o prácticas culturales, sino grupos enteros de población, tal como en su momento ocurrió en 
la Argentina, donde la omisión o sustracción del legado indígena en los estudios historiográficos y patrimoniales que impuso la Comisión Nacional de Museos y de Monumentos y Lugares Históricos afectó, no solo la idea de nación en ese país, sino su concepción de la relación entre identidad territorial y patrimonio. Situación que en su momento se extendió, no solo al caso uruguayo, donde la mayoría de la población es de raza blanca sino, paradójicamente, al brasilero, donde la mayoría de esta es de naturaleza mestiza, mulata o zamba.

Sirva de ejemplo en este último país la eufemística noción de "activación patrimonial" que al interior de la ciudad de Llorenç Prats pretendió construir un imaginario de "capital indígena" paradojicamente resaltando o suprimiendo, en orden a las directrices políticas, determinados bienes, en atención a una explícita operación de manipulación de la memoria colectiva, tal como puso en evidencia la construcción del "corredor cultural" que en 2008 creó una escenografía urbana "en consonancia" con la preservación y/o exaltación de aquellos bienes patrimoniales escogidos para el efecto, de esta forma se inventó un centro histórico acorde con las demandas del calendario cultural que promovía la institucionalidad.

Llama la atención, también en la línea de la relación invisibilización-visibilización, la situación que se presenta en la ciudad de Montevideo respecto de muchas de las obras que "decoran" los espacios públicos de la ciudad, las cuales son "rescatadas", no solo para la memoria sino para la presencia, gracias a la realización de diferentes intervenciones artísticas que de tal o cual forma interpelan al ciudadano. Ejemplos en este sentido se evidencian también en muchos otros lugares de América Latina, en el marco de una especie de moda de apropiación lúdica o crítica -en ocasiones ambas cosasdel patrimonio.

En el caso de Brasil, numerosos ejemplos dan cuenta de la importancia de llevar a cabo acciones relacionadas con la apropiación democrática del paisaje de las ciudades del que, por supuesto, la propia población y sus prácticas culturales hacen parte.

Así, por ejemplo, en la ciudad de Río de Janeiro, un análisis del paisaje urbano centrado en los espacios públicos libres y su usufructo - caso del parque lineal de Flamingo- hace pensar en su historicidad, en sus imaginarios, así como en los lazos memorísticos y sensibles que suscita en sus usuarios. Allí resulta evidente que el patrimonio no se concentra en su infraestructura y en sus dotacionales, sino que involucra los usos y las prácticas sociales de la gente que de tal o cual forma lo han hecho suyo, razón más que de peso para velar responsablemente por su preservación y cuidado con el fin de evitar, no solo la violencia que tanto aqueja a esta ciudad, sino el abandono y la degradación.

De ahí la importancia de llevar a cabo las acciones de intervención incluyente y participativa que, de la mano de la instituconalidad y de los vecinos, de tal forma favorezcan el sentimiento de pertenencia que su sustentabilidad exige. 
Otro ejemplo en Brasil, concretamente en Santa Leopoldina, estado de Spiritu Santo, liga las nociones de identidad y etnicidad a la de construcción (o destrucción) de territorialidad derivada del peso económico de sus actividades, particularmente en lo que concierne al impacto que sobre la cultura y la sociedad genera la implantación y manejo de las líneas de producción que a través de la localización de sus outsiders y sus insiders arroja inumerables saldos negativos sobre la estructura y las dinámicas tradicionales de la población.

En el ámbito del turismo religioso, tema que en este país es de particular relevancia, se destacan dos reflexiones: una en la comunidad rural de Água da Fonte, ubicada en el municipio de Farol, Paraná, donde la presencia de elementos materiales, ligados a la religiosidad popular llevaron a la idealización y consagración del Memorial Água da Fonte Profeta João Maria de Jesus, en la clara intención de promover el turismo religioso a nivel regional. En este contexto se hace visible una entre muchas maneras en que la religiosidad popular, así como el sentimiento de devoción entre residentes y visitantes, son manipulados por las formas del poder político en franca articulación con la comunidad organizada y con las políticas de preservación patrimonial.

Desde la perspectiva del turismo gastronómico y vinícola, el caso brasilero aporta, también, desde dos casos distintos, una nueva reflexión en la materia: una ubicada en la Sierra Gaúcha que involucra la relación entre imaginario, turismo y patrimonio desde la resignificación de los alimentos, particularmente la polenta, en torno a la cual no solo se llevan a cabo festivales, sino que, incluso, se desarrollan nuevos productos y derivados de esta que promueven su consumo como parte de una idea de denominación de origen que, en consecuencia, se circunscribe a la promoción de un saber local.

De esta forma se pone en evidencia - y en circulación para el consumo- no solo un determinado producto, sino una forma particular del "saber hacer artesanal" que, en consecuencia, también se promueve con el solo fin de legitimarlo, gracias a su reconocida autenticidad, la cual por supuesto es respaldada por la marca que para el efecto le otorga el lugar donde se genera.

En este sentido merece mencionarse, también, el caso de los productores de vino del sur del estado de Minas Gerais que, para enfrentar el desconocimiento que frecuentemente existe en torno al desarrollo de esta actividad en este lugar, remarcan, como una ventaja comparativa, las particularidades y diferencias entre sus formas artesanales de producción y las reconocidas formas industriales que, por demás, se llevan a cabo en el sur del país.

Desde aquí, estos abogan por el reconocimiento patrimonial de su práctica, no solo desde sus particulares formas de producción, sino desde la propia valoración del paisaje rural campesino que en todo se opone al claramente industrial de otras regiones que llevan a cabo esta misma actividad y que, cuando la enseñan al público, lo hacen desde una perspectiva museística lejana en todo a la forma viva en que los productores rurales exponen la suya. 
Del mismo modo, el contexto brasilero pone en evidencia dos situaciones más que, no siéndole exclusivas, sirven de referencia para analizar, particularmente en el ámbito lationamericano, por un lado, la relación entre derribos patrimoniales e higienización espacial y, por otro, también por la vía de la higienización socio-espacial, la turistificación y consecuente vanalización de entornos patrimoniales o claramente identitarios. En el primer caso, se tiene como ejemplos, entre muchos otros, el derribo del teatro 7 de Abril de la ciudad de Pelotas; el del terreiro Pedra Branca en el estado de Seará primer terreiro de la religión afro-brasilera patrimonializado en ese país-; y el sistemático derribo de bienes patrimoniales en la ciudad de Mossoró, estado de Rio Grande do Norte. En el segundo, las intervenciones efectuadas en la favela Vidigal de Río de Janeiro y en la zona de Pelourinho en Salvador de Bahía.

En el caso del teatro 7 de Abril lo que ocurre es la puesta en marcha de una política de demolición de teatros antiguos en todo Brasil, paradojicamente hecho por el Servicio Nacional de Teatro al Servicio Nacional del Patrimonio Histórico y Artístico Nacional (SPHAN) en 1963, donde contrastan los valores atribuidos al teatro por parte de la esfera nacional (SPHAN) y lo que al mismo otorga el ámbito local que, de suyo, los vive como patrimonio (prefectura, dirección de teatro y, por supuesto, los propios pobladores). Mientras que la preocupación local se centraba en la posibilidad de abrir con el derrumbe del teatro un espacio a la especulación inmobiliaria, lo que le interesaba al SPHAN era la originalidad de las intervenciones pasadas hechas para lograr su preservación.

En cuanto al derribo del terreiro Pedra Branca son de destacar las resistencias de la población a la demolición de este importante referente de la cultura afro-brasilera, acción que representó un quiebre de paradigma por cuanto el derribo se llevo a cabo a través de un violento dispositivo que negó la posibilidad de cualquier registro o protección, toda vez que a finales de la dictadura, cuando tal situación se dio, no existía nungún tipo de política de protección de bienes culturales inmateriales.

En este sentido, el caso de la ciudad de Mossoró es particularmente drámatico, pues la misma se autopromociona como "capital cultural", no obstante la práctica sistemática e ininterrumpida de destrucción de su patrimonio, y dada la diversa manera como se entienden los valores patrimoniales en los ámbitos federal y regional. Esta situación hace necesario considerar las especificidades de cada territorio a partir de los valores arraigados en la historia local, de suerte tal que se revise y reconsidere la política y, en consecuencia, se aumente la valoración y preservación del patrimonio edificado a nivel regional.

En cuanto a la vanalización turistificante de los lugares patrimoniales, la década de los años $70 \mathrm{del}$ siglo pasado en Brasil es rica en ejemplos deplorables, casos como el de la favela de Vidigal, o el de Pelourinho dan cuenta de la invasión de infraestructuras construídas exclusivamente para el turismo 
en una clara acción orientada a aumentar el costo del suelo so pretexto de incrementar el atractivo.

Un tema que no se puede dejar de lado en el debate patrimonial en el caso brasilero, aunque también aplicaría para el de Uruguay, Paraguay, Haití y, entre otros, el de República Dominicana, es el que tiene que ver con la etnicidad racial donde se pone de manifiesto la ocasional preponderancia, de acuerdo con la política de turno, de una u otra decisión. Sirva de ejemplo el proyecto "O pampa negro" que en el sur de Brasil puso en evidencia el conflicto entre el patrimonio "blanco" de élite (casasgrandes) y el patrimonio afrodescendiente, ya sea material, como las senzalas o barracas destinadas a los esclavos, o inmaterial, como la "Dança dos orixás" que reviven la tradición de la religión Lucumí.

\section{El papel de los actores sociales en la construcción de una política orientada a integrar identidad, globalización y patrimonio en los procesos de gestión, planeación, promoción y ordenamiento del territorio}

Algo que dejó en claro el Coloquio es que la conservación patrimonial, particularmente entendida desde la perspectiva de la identidad territorial, no es un asunto de competencia exclusiva de la política o las autoridades, sino que involucra también a la ciudadanía y a los diferentes actores sociales, por cuanto no compete tan solo a la simple conservación de bienes heredados, ya sea del orden material o inmaterial, sino que tiene que ver con la manera como se organiza y ha de organizar la vida en colectivo; de ahí la relevancia del patrimonio para abordar temas como el del ordenamiento del territorio ligado a una gestión y una planeación del mismo con sentido local, esto es, en clara concordancia con lo que la gente es y espera.

Aspiración que choca en primer lugar con la falta de controles, no solo de las administraciones locales y nacionales, sino también de la propia población que, por falta de conocimiento, de interés o de integración en los procesos de toma de decisiones, dejan las mismas en manos de sus gobernantes, en muchos casos aliados de los intereses mercantilistas que de tal suerte ponen en venta, normalmente al turismo y/o al consumo, no solo bienes concretos, sino entornos enteros de ciudad. Es como si el patrimonio no tuviese dolientes o, peor aún, no fuera pensado por sus detentores, en primer lugar, los institucionales, quienes, de suyo, están mandados a ello. Desde aquí resulta evidente que hace falta información, participación y compromiso de las respectivas comunidades, así como verdaderos y amplios planes de educación patrimonial.

La expulsión o desplazamiento de población (gentrificación) es un indicador de los efectos de una planeación y una gestión del territorio que poco o nada tiene en cuenta a la gente, sobre todo en los centros urbanos de ciudades que tienen, o buscan tener, una vocación turística, ejemplo de ello los casos antes señalados de Pelourinho en Salvador de Bahía y de Vidigal en Río de Janeiro donde la 
población se siente molesta, y con razón, de que sus ciudades o sus centralidades patrimoniales o identitarias estén pensadas sobre todo para su explotación turística.

Un caso emblemático que contradice esta tendencia es el de San Salvador de Jujuy, en el noroeste argentino, donde la ciudad fue pensada, en términos de ordenamiento territorial y urbano, a partir de una propuesta de gestión patrimonial creativa ocupada en lograr un alto grado de estetización por la vía de la participación ciudadana, para lo cual se llevaron a cabo importantes actividades de estudio, valoración y difusión de naturaleza interdisciplinar que involucraban, no solo la identificación de las diveras formas de saber, conocer y vivir la ciudad, sino la entrada en valor de las mismas en las decisiones político administrativas en lo tocante al territorio y a las territorialidades, por definición, siempre patrimoniales; esto con el fin de promover la mejora de la calidad de vida, el desarrollo económico y la educación.

Cabe mencionar en el mismo sentido el caso de la ciudad de Paulo Frontin, en el estado de Paraná, donde la correlación entre la política pública de ordenamiento territorial y el imaginario de los pobladores, establecido en 2018 a través de una encuesta de opinión pública, permitió concluir la necesidad de incluir el estudio de la historia de la ciudad y de sus manifestaciones populares en las audiencias que involucran los conflictos políticos y simbólicos en la gestión del territorio, esto en el entendido de asumir que el mismo es un patrimonio colectivo.
En lo que respecta a la invisibilización de ciertos actores en los procesos de planeación y/o gestión del patrimonio - como personas en situación de calle, comunidades indígenas, población afrodescendiente, personas de la tercera edad o en condiciones de discapacidad que por situaciones geográficas o sociales se encuentran en relativo confinamiento, o representantes de cualquier otra clase de minoría - cabe pensar, primero, en la adopción de unas claras políticas equitativas e incluyentes y, segundo, en la mediación de otros actores-educadores o gestores educativos, las $\mathrm{ONG}$, entre otros posibles, universidades.

A fin de cuentas, la inclusión y, con ella, la participación no son un lujo o una concesión democrática, sino la base de la democracia misma, de ahí la necesidad de establecer los adecuados criterios metodológicos que permitan hacerla efectiva tanto en la formulación de estrategias de valorización y divulgación del patrimonio como en su conservación. Sirva de ejemplo el caso del patrimonio industrial donde la recuperación de la memoria de estos escenarios debería involucrar los relatos de sus protagonistas.

En cuanto a los criterios de intervención de los bienes patrimoniales, se puso en evidencia la necesidad de un posicionamiento crítico que permita identificar los conflictos e intereses en materia de uso y apropiación social de los mismos; esto con el fin de articular de manera coherente grados de deterioro y niveles de intervención, al fin y al cabo, todo problema de intervención material es un 
problema de interpretación de la obra existente y de asignación de nuevos sentidos sobre la misma.

Un aspecto crucial en la valoración de los bienes patrimoniales derivado de la participación ciudadana es el que proviene de su debida comprensión, para lo cual llevar a cabo actividades pedagógicas (in) formativas resulta de especial relevancia, tal como lo ha demostrado en el caso de Brasil el proyecto de educación patrimonial de Rutas por el Centro Histórico de Belém (Premio Rodrigo Melo Franco de Andrade), que consiste en el desarrollo de recorridos geo-turísticos por la ciudad, pensados para estudiantes, habitantes locales y visitantes eventuales, y el de Vigías del Patrimonio que en la misma tónica lleva a cabo recorridos en diversos lugares de Colombia desde hace varios años.

Qué no decir del papel de los habitantes de aquellos entornos patrimoniales, que por una u otra razón ha sido sentenciados de derribo, en lo que concierne a la necesidad de su visibilización a través del desarrollo de intervenciones sobre los mismos que den cuenta de la identidad que, de tal o cual forma, no solo los liga a estos, sino que les otorga a tales lugares razón y sentido.

\section{Consideraciones generales}

La conclusión es simple, aunque compleja en sus implicaciones: el patrimonio es algo que, por ser de todos, compete a todos su cuidado y preservación. El avance de la presión inmobiliaria sobre las áreas donde se localizan bienes patrimoniales, donde el valor del suelo trasciende el valor edilicio de los bienes catalogados, alerta sobre la necesidad de adecuar y articular instrumentos de intervención urbanísticos, fiscales y económicos para preservar los bienes tangibles y la memoria colectiva de lugares singulares.

En este sentido se evidencia un claro distanciamiento entre la gestión del patrimonio y la gestión del terrrorio, así como la carencia de un marco que permita pensar las dos, de suerte tal, que las metodologías para efectuar análisis y relevamientos en uno u otro caso no resulten antagónicas, tal como frecuentemente sucede cuando interviene el aspecto económico y los enfoques y prioridades se establecen exclusivamente desde este.

Por su parte, el concepto de identidad, ligado al de territorialidad, es abordado desde diferentes disciplinas y puntos de vista que van desde perspectivas filosóficas y psicológicas, hasta maneras más "funcionalistas" de entender el mismo a la luz de la historia, la antropología, la sociología o la arquitectura.

En lo que concierne al uso de este en el ámbito urbano, frecuentemente existen dos miradas que se contraponen, una esencialista que busca describir y entender la identidad de las ciudades, y con ella su territorialidad, desde una idea de "unicidad" - concepción particularmente querida por los políticos en campaña-, y otra que entiende la misma desde una perspectiva más dinámica y "constructivista", desde la cual esta se entiende de una manera heterogénea y procesual en la cual caben numerosas identidades ligadas, de cualquier 
forma, a consecuentes formas de territorialidad, en cualquier caso atenientes a un imaginario simbólico, a una idea que reune y/o integra a un grupo determinado de personas.

Ahora bien, en un mundo global donde por todas partes se atestigua la movilidad, ¿Cómo debe entenderse la territorialidad, más aún, la identidad territorial ligada a una forma u otra de patrimonio? ¿Dónde y cómo ver y entender la misma? (Santos, 1996b). Sin lugar a dudas en las múltiples formas en que esta se pone de manifiesto a través de los intercambios (políticos, económicos, sociales, ambientales y culturales), los que de suyo ponen en evidencia, no solo actores, sino intereses, desde los cuales se entra en relación con "el otro", cualquiera que este sea o represente.

De esta forma la identidad territorial, más que una expresión tautológica pues desde una perspectiva psicologizante tendríamos que aceptar que toda identidad es territorial, es lo que nos define en el marco de lo que ponemos en juego a través de nuestros intercambios: un lugar de poder o de fragilidad, una intencionalidad, unos valores o unos bienes particulares - materiales o inmateriales-, en cualquier caso, algo nuestro que de tal o cual forma nos ex-pone, es decir, nos pone afuera, nos muestra en nuestra mismidad.

Desde esta perspectiva, ¿Qué es la globalización sino una feria de mismidades -identitarias y territoriales - puestas en circulación en torno a un paquete de valores impuestos universalmente que pretenden subsumirlas a la luz de unos determinados intereses? ¿Y si más allá de "pensar globalmente para actuar localmente" y de tal suerte validar el discurso hegemónico, aprendemos a pensar localmente para actuar e impactar de manera global? ¿No estaríamos abriendo un espacio real, no retórico, a la multi y a la inter culturalidad desde la cual no tenemos que dejar de ser de un lugar para sentirnos responsables de todos por igual?

A fin de cuentas, si por el lado del consumo la globalización tiende a desterritorializarnos a través de la homogenización, por el lado del patrimonio, la apropiación que hagamos de este nos reterritorializa gracias al singularismo y la heterogenización.

Lo que este mundo móvil y su feria de racionalidades e intercambios pone de manifiesto es que tanto la identidad territorial como el patrimonio no son valores inmanentes e inmutables, sino construcciones históricas en permanente transformación, validación y legitimización. Si en algo debemos afirmarnos hoy en día es en el cambio, mismo desde el cual aquello que somos no solo está en deuda con lo que heredamos, sino con el propio devenir de los tiempos que de tal o cual forma nos talla pues, como anotaba Ortega, somos en nuestras circunstancias, lo cual no quiere decir que estemos predeterminados o inexorablemente condicionados por ellas, sino por la interacción que con ellas desarrollemos. Una interacción en la que a la vez que nos formamos damos forma al mundo que nos rodea (Santos, 1996a).

En este contexto, la gran paradoja es que aquello que denominamos patrimonio, para aludir al 
conjunto de bienes heradados que de tal o cual forma quieren ser inequívocos signos de nuestra identidad - ligada no solo a un territorio sino, sobre todo, a una idea de él- son de otra parte prueba, precisamente, de aquello que ya no somos, de aquello que decidida o históricamente hemos dejado de ser.

¿Dónde esta el patrimonio, entonces? ¿En dónde buscar los signos de nuestra identidad territorial? Acaso en la manera como ex-ponemos el paquete de valores que portamos (tan heredado como construido en el tiempo) cuando entramos en relación con un bien o un lugar cualquiera, de ahí que, así como el patrimonio cada vez está menos en las cosas y más en la relación que establezcamos con ellas, la identidad está cada vez menos atada a unos lugares o a unos signos ciertos y más a la identificación que establezcamos con unos y otros, y a través de ellos, con el mundo que los ofrezca.

Valga resaltar en este sentido una de las ponencias del Coloquio que, en atención a una reflexión acerca de la movilidad del mundo de hoy, ponía como ejemplo el caso de los monjes capuchinos que, en razón de su actividad misional o misionera, viven permanentemente en movimiento y su único patrimonio son los recuerdos de sus viajes, entre otras cosas, manifiestos en sus trajinadas maletas y en sus fotografías.

¿Qué decir entonces de los bienes declaradamente patrimoniales por parte de la institucionalidad competente? ¿Qué decir de aquellos otros bienes culturales, tanto materiales como inmateriales, que sin ser declarados de tal forma hacen parte de la identidad de un grupo humano? ¿Qué decir del papel del turismo, en ambos casos atento siempre a captar "ventajas comparativas" para rentabilizarlas al ofertarlas de tal suerte en el mercado?

El reto, en cualquier caso, declara el Coloquio en sus conclusiones, no es la explotación sino la conservación; otra cosa es que la primera se ponga al servicio de la segunda, aún en contravía de lo que al parecer dictan nuestros tiempos para los cuales el fin es la explotación y el medio es la conservación.

El hecho es que el turismo ha llegado para quedarse, no en vano la industria cultural se ha convertido en uno de los más importantes renglones de la economía a nivel global, lo cual hace necesario, y urgente, generar políticas y estrategias sostenibles de intervención, habilitación y preservación de aquellos lugares o entornos de marcado valor patrimonial, con el fin de defenderlos del impacto expoliador y depredador del turismo.

En este contexto es indispensable tanto formar recurso humano local idóneo para enfrentar las situaciones de sobrecarga sobre los bienes patrimoniales como concebir sistemas de gestión y ordenamiento participativos que permitan la coexistencia de sistemas exógenos y locales orientados al mutuo beneficio. 
Haesbaert, R. (2011). El mito de la desterritorialización. Del fin de los territorios a la multiterritorialidad. Siglo XXI.

RIGPAC (2018). Memorias. $V$ Coloquio Internacional. https://vcoloquiointernacion.eventize.com.br/index. php?pagina $=23$

Santos, M. (2008). La naturaleza del espacio. Técnica y tiempo. Razón y emoción. Ed USP.

Santos, M. (1996a). Metamorfosis del espacio habitado. Oikos -Tau.
Santos, M. (1996b). De la totalidad al lugar. Oikos -Tau.

Yory, CM. (2006). Ciudad, Consumo y Globalización: caracterización de las grandes metrópolis en el comienzo de siglo. Una mirada desde la relación entre consumo y sociedad (Prólogo de Armando Silva) Ed. Pontificia Universidad Javeriana.

Yory, C.M.(2002). Del Monumento a la Ciudad. Ed. Pontificia Universidad Javeriana.

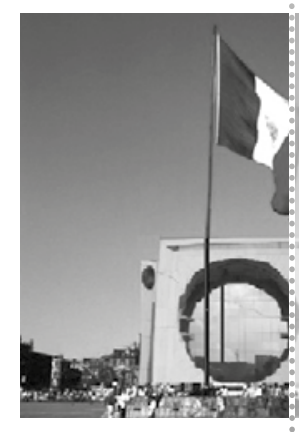

Fotomontaje Edificio del sector de Santa Fé

Carlos Mario Yory, 2009 
